\title{
LAS OBLIGACIONES INTERNACIONALES DE LOS ESTADOS MIEMBROS DE LA ORGANIZACIÓN DE ESTADOS AMERICANOS EN LA LUCHA CONTRA EL TERRORISMO
}

\section{DIEGO RODRÍGUEZ PINZÓN}

\section{American University \\ drodrig@wcl.american.edu \\ Artigo submetido em espanhol}

Este artículo es una trascripción modificada y referenciada de la presentación realizada en el Seminario Internacional Derechos Humanos y Terrorismo que se llevó a cabo en México el 12 de septiembre del 2006.

Las páginas de internet citadas se consultaron en abril del 2007. 


\section{ANTECEDENTES}

En los últimos años, el mundo ha sido testigo de acciones atroces que han llevado a la comunidad internacional a incluir en su agenda de trabajo la adopción de numerosas iniciativas para combatir ataques terroristas. La Organización de Estados Americanos (oea), teniendo en cuenta que el terrorismo constituye una amenaza a la seguridad internacional y pone en peligro la protección eficaz de los derechos humanos ${ }^{1}$, ha adoptado una serie de acciones políticas, jurídicas y judiciales encaminadas a guiar a los Estados miembros en la lucha contra el terrorismo.

Se debe empezar por mencionar que el hemisferio americano, desafortunadamente, ha sido escenario de acciones terroristas durante varias décadas. Estas acciones se han presentado en el con texto de gobiernos autoritarios que, utilizando como pretexto la supuesta amenaza terrorista, adelantaron acciones concertadas contra la población civil ${ }^{3}$, y también han sido ejecutadas por actores armados disidentes que intentan deponer gobiernos establecidos de forma democrática ${ }^{4}$. Es así como hemos visto en la historia americana acciones estatales que ocasionaron violaciones graves y sistemáticas de derechos humanos, tales como desapariciones forzadas, masacres y otras prácticas infames perpetradas contra la población civil y presuntos miembros de grupos terroristas ${ }^{5}$. De otra parte, también hemos sido testigos de las acciones emprendidas por gobiernos electos y democracias incipientes que tomaron medidas de facto y de jure, que menoscababan los derechos humanos y que, de alguna manera, no se diferenciaban de las acciones perpetradas por las dictaduras en el Cono Sur y Centroamérica en décadas pasadas.

Asimismo, como parte de este cuadro complejo de la historia de las Américas, está el papel que han tenido los actores no estatales involucrados en conflictos armados de carácter interno. Estos grupos han emprendido actividades que deterioran en forma masiva los derechos de la población civil, a través de artefactos explosivos, secuestros, desapariciones forzadas, entre otras ${ }^{6}$.

\section{RELACIÓN ENTRE LOS INSTRUMENTOS INTERNACIONALES RELE- VANTES}

Es precisamente en el contexto anterior, el de la lucha antiterrorista, en el que debemos analizar puntualmente cómo se pueden articular o armonizar los instrumentos legales de carácter internacional, para determinar el alcance que pueden tener las medidas adoptadas por los Estados en la lucha contra el terrorismo. En otras palabras, explorar cómo se correlacionan las convenciones regionales de derechos humanos ${ }^{7}$ con aquellas normas internacionales desarrolladas específicamente dentro del contexto de la lucha contra el terrorismo, como lo es la Convención Interamericana contra el Terrorismo ${ }^{8}$.

\section{CONFLUENCIA ENTRE LAS OBLIGACIONES DE DERECHOS HUMA- NOS Y LAS DE LUCHA ANTITERRORISTA}

En el sistema interamericano, al contrario de lo que usualmente se pregona, estas dos esferas de instrumentos buscan objetivos legítimos análogos. Es así como al revisar los objetivos y las obligaciones fundamentales que se establecen en la Convención Americana sobre Derechos Humanos (cadh) y en la Convención Interamericana contra el Terrorismo, podemos ver que ambos instrumentos establecen obligaciones muy similares en lo que se refiere a la preservación de intereses vitales de nuestros países, tales como salvaguardar el derecho a la vida, a la integridad personal, a la libertad, a la propiedad, entre otros. De igual forma, podemos observar cómo el lenguaje de la Convención Interamericana contra el Terrorismo no difiere, en muchos aspectos, del lenguaje que se ha desarrollado en el contexto de las convenciones de derechos humana. 
Partiendo de este análisis, podemos identificar las obligaciones que se derivan de estas dos dimensiones del derecho internacional: por una parte, tenemos la obligación de respetar y garantizar los derechos humanos contenidos en la $\mathrm{CADH}^{9} \mathrm{y}$, por la otra, las obligaciones de prevenir, sancionar y eliminar el terrorismo, contenidas en la Convención Interamericana contra el Terrorismo ${ }^{10}$. De cierta manera se puede decir que no existe dificultad para armonizar estos instrumentos, ya que las obligaciones que se desprenden de estos dos regímenes internacionales convergen en la mayoría de las circunstancias. Con respecto a la población en general, la lectura de ambos tipos de tratados es bastante clara, ya que en ambas convenciones, el Estado está llamado a ser el principal garante del cumplimiento de esas obligaciones internacionales en su jurisdicción y en ese sentido, el Estado debe hacer todo lo que esté a su alcance para proteger a las personas y para sancionar a los agresores, incluyendo la adopción de medidas conducentes a evitar actos terroristas.

\section{LOS DERECHOS HUMANOS COMO LIMITACIÓN A LOS MEDIOS DE LUCHA CONTRA EL TERRORISMO}

Sin embargo, el análisis se hace un poco más complejo con relación a los derechos humanos que tienen las personas acusadas de perpetrar actos terroristas, pues se trata de distinguir qué tipo de medidas puede adoptar el Estado sin que esos derechos fundamentales se vean vulnerados en el proceso. En este aspecto, las normas de derechos humanos son guías obligadas sobre la forma como se debe combatir a los grupos señalados como terroristas.

Para poder hacer un análisis completo de la correlación existente entre estos dos regímenes, se debe entrar a identificar el marco de acción que tienen los Estados en la lucha contra el terrorismo bajo la perspectiva de la jurisprudencia y de los estándares de derechos humanos ya establecidos dentro del sistema interamericano. Tenemos entonces, de una parte, las medidas antiterroristas que el Estado desee adoptar y, por otro lado, tenemos la jurisprudencia y los estándares de derechos humanos que van a señalar los límites de dichas medidas antiterroristas que pretenden adoptar los Estados.

De igual forma, es importante resaltar que las mismas convenciones nos dan luces sobre la correlación que existe entre estos tratados. Es así como la Convención Interamericana contra el Terrorismo, en su artículo 15, insta a los Estados parte a respetar el Estado de derecho, los derechos humanos y las libertades fundamentales, al momento de adoptar medidas contra el terrorismo ${ }^{11}$. Asimismo, menciona que ninguna disposición de la cadh debe ser interpretada de tal forma que los derechos de las personas se vean menoscabados, conforme al derecho internacional ${ }^{12}$. Es decir, que la misma Convención contra el Terrorismo le impone unos límites claros a los Estados, con relación a las medidas que pretendan adoptar, y obliga expresamente a tener en cuenta a los tratados de derechos humanos como la CADH. Por lo tanto, el desconocimiento de las normas de derechos humanos no sólo sería una violación de la cadh sino también de la Convención Interamericana contra el Terrorismo.

\section{SUSPENSIONES DE DERECHOS AUTORIZADAS POR LOS TRATADOS DE DERECHOS HUMANOS}

La cadh permite en circunstancias excepcionales y bajo condiciones precisas ${ }^{13}$, que los Estados parte suspendan temporalmente el ejercicio de ciertos derechos protegidos por la cadh. ${ }^{14}$ Es decir, que los Estados "en caso de guerra, de peligro público o de otra emergencia que amenace la independencia o seguridad del Estado parte" 15 y en la medida y por el tiempo estrictamente limitados a las exigencias de la situación, podrán suspender el ejercicio de aquellos derechos que no estén 
enumerados en el artículo 27 de la $\mathrm{CADH}^{16}$. De esta forma, la cadh da un margen de acción a los Estados para que adopten las medidas que consideren necesarias en la lucha contra el terrorismo, siempre y cuando respeten los criterios de proporcionalidad y legitimidad que se les exige en la adopción de este tipo de medidas ${ }^{17}$.

Asimismo, la Corte Interamericana de Derechos Humanos (Corteidh), en sus opiniones consultivas OC-8/87 y OC-9/87, ha establecido criterios relativos a la vigencia de las garantías judiciales en estados de emergencia. La Corteidh indicó que “...la implantación del estado de emergencia no puede comportar la supresión o la pérdida de efectividad de las garantías judiciales que los Estados Parte están obligados a establecer" ${ }^{\prime 1}$. De esta forma la Corteidh dejó en claro que las garantías judiciales establecidas en la cadh no son derogables bajo ninguna circunstancia, lo cual adquiere cierta relevancia en la lucha contra el terrorismo, si se tiene en cuenta que los Estados no podrán suspender dichas garantías so pretexto de la lucha contra ese fenómeno.

\section{GUÍAS DESAROLLADAS POR LOS ÓRGANOS DE DERECHOS HUMA- NOS DEL SISTEMA I NTERAMERICANO PARA LA ADOPCION DE MEDIDAS ANTITERRORISTAS}

Evidentemente los órganos de protección de derechos humanos de la oea, la Comisión Interamericana de Derechos Humanos (cidh) y la Corteidh, han desarrollado estándares detallados, utilizando sus correspondientes potestades convencionales, estatutarias y reglamentarias. A continuación mencionaremos algunos de los informes y acciones más recientes de estos órganos sobre la materia.

\section{EL INFORME DEL 2002 SOBRE TERRORISMO, DERECHOS HUMANOS Y OTROS INFORMES GENERALES DE LA COMISIÓN INTERAMERICANA E DERECHOS HUMANOS}

La primera modalidad de acción es la preparación de informes especiales o generales por parte de la CIDH. Es particularmente importante hacer referencia al informe especial que la CIDH emitió en el año 2002, denominado el "Informe sobre Terrorismo y Derechos Humanos"19. Este constituyó una de las primeras acciones comprensivas de un organismo intergubernamental luego de los hechos de septiembre 11 de 2001. En dicho informe, la CIDH realizó un análisis exhaustivo sobre la materia y formuló recomendaciones a los Estados miembros de la oea sobre cómo deben dirigir sus políticas antiterroristas, para que cumplan cabalmente con las obligaciones internacionales en materia de derechos humanos ${ }^{20}$. Este informe se ha convertido en un documento de referencia crucial, pues constituye una clasificación de los estándares y jurisprudencia de derechos humanos del sistema interamericano sobre los aspectos más relevantes para la lucha contra el terrorismo.

En el informe, la CIDH establece la forma cómo se deben aplicar las normas de derechos humanos y de derecho internacional humanitario (DIH) en el contexto de la lucha contra el terrorismo ${ }^{21}$. Es decir, señala la forma de aplicación de ambos regímenes internacionales, lo cual, para los Estados del hemisferio inmersos en conflictos armados de carácter interno, resulta particularmente útil. Vale resaltar que la práctica de aplicar estos dos ámbitos, con el fin de determinar cuáles son los estándares aplicables en la lucha contra el terrorismo, es un ejercicio que se ha venido consolidando en la práctica del sistema interamericano.

De igual forma la CIDH analiza el derecho a la vida, a la libertad personal, al debido proceso, la prohibición contra la tortura, contra los tratos crueles, inhumanos y degradantes, el principio de nodiscriminación y de otros derechos, tales como el derecho a la libertad de expresión, a la libertad de 
reunión, a la propiedad, a la privacidad, entre otros. La CIDH realiza un análisis exhaustivo de cada uno de estos derechos, sobre la base de los estándares de derechos humanos y DIH. Luego trata aspectos relacionados con trabajadores migratorios, el derecho relacionado con asilo, refugiados y derechos de los extranjeros, los cuales son temas que la CIDH ha identificado como críticos dentro del contexto de la lucha contra el terrorismo en la era post-Septiembre 11 .

\section{RECOMENDACIONES DEL 2006 PARA LA PROTECCIÓN DE LOS DERECHOS HUMANOS POR PARTE DE LOS ESTADOS MIEMBROS DE LA ORGANIZACIÓN DE ESTADOS AMERICANOS EN LA LUCHA CON- TRA EL TERRORISMO}

Posteriormente a la adopción del informe antes mencionado, la CIDH continuó monitoreando la situación frente al nuevo ambiente que se fue gestando en el hemisferio después de los atentados del 11 de septiembre. Es así como la CIDH formuló en el 2006, a manera de seguimiento, una serie de recomendaciones que tienen como propósito aclarar y reforzar el Informe sobre Terrorismo y Derechos Humanos ${ }^{22}$. Dichas recomendaciones surgieron como resultado de un esfuerzo común realizado por varios organismos de la oea. Es así como la Asamblea General de la OEA, en la Resolución 203 del 8 de junio de $20042^{23}$, decidió solicitar a la CIDH que, con el apoyo del Comité Interamericano contra el Terrorismo (CICTE), formulara recomendaciones a los Estados miembros con relación a la protección de los derechos humanos en la lucha contra el terrorismo ${ }^{24}$. La CIDH, para tal efecto, convocó a varias organizaciones no gubernamentales a una audiencia de carácter general con el objetivo de obtener sus puntos de vista sobre el contenido y la naturaleza de las recomendaciones $^{25}$. Así, la CIDH asistió a sesiones del cicte y a su vez el secretario del cicte participó en una reunión oficiosa con el plenario de la CIDH para considerar asuntos relacionados con la protección de los derechos humanos en la lucha antiterrorista ${ }^{26}$. Asimismo, tuvo en cuenta los resultados de la Reunión de Expertos Gubernamentales, convocada por el Consejo Permanente, en la cual los gobiernos tuvieron la oportunidad de presentar sus observaciones acerca del contenido de las recomendaciones ${ }^{27}$. Finalmente, la $\mathrm{CIDH}$ presentó el documento de recomendaciones al Consejo Permanente de la oea en mayo de 2006. Este informe de recomendaciones presenta un lenguaje más actualizado y sintético, que resume en forma clara y esquemática las recomendaciones que ya había emitido desde el 2002 a los Estados.

\section{INFORMES SOBRE PAÍSES}

De esta manera se deben resaltar los informes especiales de países ${ }^{28}$ que realiza la CIDH. Estos informes analizan la forma cómo los Estados garantizan y aseguran la vigencia de los estándares de derechos humanos y DIH. Un ejemplo importante y relevante para el tema que nos ocupa es el Tercer Informe sobre la Situación de los Derechos Humanos en Colombia.29 En dicho informe, la Comisión analiza la situación del conflicto armado colombiano a la luz de las normas de derechos humanos y dih. En particular, hace referencia al Protocolo Adicional $\mathrm{II}^{30}$ y al artículo 3 común de los cuatro Convenios de Ginebra ${ }^{31}$, para luego identificar violaciones, no solamente por parte de agentes estatales, sino también de grupos armados ilegales no estatales. Es en este contexto de los informes generales en donde la CIDH ha podido desarrollar con mucha más amplitud la aplicación de estas normas internacionales a situaciones de conflicto para evaluar la conducta, tanto de actores estatales como no estatales, todos ellos involucrados en acciones que podrían calificarse como terroristas. 


\section{SISTEMA DE CASOS}

Otra forma de respuesta que ha resultado de vital importancia en el sistema interamericano, es precisamente la del sistema de casos o peticiones individuales. Esta modalidad de supervisión ha tenido gran importancia en situaciones en las que se han adoptado medidas antiterroristas que claramente vulneraban los estándares internacionales. En el caso peruano, por ejemplo, tanto la Corteidh como la cidh abarcaron de manera exhaustiva el tema del "terrorismo de Estado" como forma de reacción ante la amenaza de grupos alzados en armas que utilizaron sistemáticamente

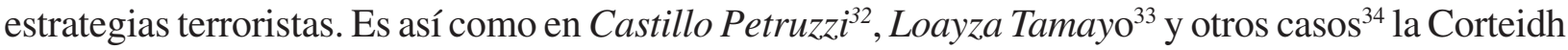
ha analizado la situación del Perú en el contexto de las violaciones sistemáticas de derechos humanos, entre otros, bajo el régimen de Fujimori. En estas sentencias la Corteidh aportó estándares que resultan de vital importancia en el análisis de las iniciativas estatales en la lucha contra el terroris$\mathrm{mo}^{35}$. De acuerdo con la CorteIDH, "las necesidades de la investigación y las dificultades innegables del combate al terrorismo no deben acarrear restricciones a la protección de la integridad física de la persona" 36 . De igual forma la Corteidh mencionó que todo uso innecesario de la fuerza constituye un menoscabo al derecho a la dignidad humana ${ }^{37}$. Asimismo, la Corteidh también abordó la adopción de normas nacionales violatorias de la $\mathrm{CADH}$, que vulneraban principios básicos del debido proceso, tales como el non bis in idem y el principio de legalidad ${ }^{38}$.

Existen otros casos en que la Corteidh señala claramente la forma como los Estados deben tener siempre en cuenta los límites normativos existentes en el tema de la lucha contra el terrorismo. Es así como al tratar el tema de desapariciones forzadas, en casos emblemáticos como el de Velásquez Rodríguez vs. Honduras ${ }^{39}$ y Bámaca Velásquez vs. Guatemala ${ }^{40}$, la CorteIDH, luego de reconocer la facultad que tienen los Estados de garantizar la seguridad dentro de su territorio, también establece límites a este accionar del Estado. La CorteIDH en dichas sentencias claramente expresa que:

Está más allá de toda duda que el Estado tiene el derecho y el deber de garantizar su propia seguridad. [...] Pero, por graves que puedan ser ciertas acciones y por culpables que puedan ser los reos de determinados delitos, no cabe admitir que el poder pueda ejercerse sin límite alguno o que el Estado pueda valerse de cualquier procedimiento para alcanzar sus objetivos, sin sujeción al derecho o a la moral ${ }^{41}$.

La Corteidh también ha tenido aportes sustanciales en materia de impunidad, que se encuentra íntimamente ligada a la lucha contra el terrorismo. Es así como, en el caso Barrios Altos vs. Perút ${ }^{42}$, por primera vez la Corteidh declaró que ciertas normas de amnistía adoptadas por los Estados eran incompatibles con la cadh. En dicha sentencia la Corteidh fue enfática al afirmar que "...son inadmisibles las disposiciones de amnistía, las disposiciones de prescripción y el establecimiento de excluyentes de responsabilidad que pretendan impedir la investigación y sanción de los responsables de las violaciones graves de los derechos humanos"43.

De igual forma, agregó que la aprobación y promulgación de este tipo de leyes, violan per se la CADH y comprometen automáticamente la responsabilidad internacional del Estado.44 Con esta sentencia la CorteIDH reafirmó la postura que la CIDH había desarrollado, en este mismo sentido, con relación a las leyes de amnistía que fueron adoptadas en países como Argentina, Uruguay, Chile y El Salvador ${ }^{45}$.

Otro aspecto importante, desarrollado a través de casos individuales, es la responsabilidad que le puede caber al Estado si permite el accionar de grupos terroristas en su jurisdicción. En el caso de Pueblo Bello vs. Colombia ${ }^{46}$, la Corteidh estableció, por primera $\mathrm{vez}^{47}$, que el Estado puede llegar a ser responsable bajo la $\mathrm{CADH}$ por las actividades de grupos privados, sin que necesariamente estos 
hayan actuado con la aquiescencia o tolerancia del Estado. Es decir, que las acciones de estos grupos armados no comprometen directamente la responsabilidad del Estado ${ }^{48}$, pero que pueden llegar a comprometerla, en la medida en que el Estado no prevenga y no tome las medidas necesarias contra las acciones de estos grupos armados ilegales, cuando esté en la posibilidad de hacerlo ${ }^{49}$.

Por otra parte, el sistema interamericano cuenta con el trabajo que la cidh ha venido desarrollando en el contexto de las peticiones individuales. En este punto, es importante resaltar, que la CIDH, a diferencia de la CorteIDH, tiene una jurisdicción mucho más amplia con relación al número de Estados que supervisa en el sistema y de los instrumentos que utiliza para tal efecto. La CIDH supervisa Estados no solamente bajo la $\mathrm{CADH}$, sino que además supervisa a todos los Estados miembros de la oea, bajo la Declaración Americana de los Derechos y Deberes del Hombre $(\mathrm{DADDH})^{50}$. En este sentido, la CIDH puede desplegar sus potestades estatutarias para redactar informes, realizar visitas in loco, decretar medidas cautelares, facilitar soluciones amistosas y adicionalmente recibir peticiones con relación a aquellos Estados que no han ratificado la $\mathrm{CADH}^{51}$.

Debemos resaltar que el sistema de peticiones individuales de la CIDH es el único mecanismo que existe con nivel internacional, para presentar denuncias individuales contra los Estados Unidos de América (EUA) por violaciones de derechos humanos ${ }^{52}$. La CIDH tiene la potestad de monitorear, el desempeño de derechos humanos de EUA bajo la $\mathrm{DADDH}^{53}$, y aunque este sistema de protección no tiene un fundamento normativo óptimo, es el sistema por medio del cual los Estados miembros de la OEA (incluyendo EUA) le confirieron mandato a la CIDH para que realizara dicha supervisión. Esto es de suma importancia, ya que en este contexto se han presentado peticiones individuales en contra EUA, relacionadas con invasiones o con actividades extraterritoriales por parte de las fuerzas militares estadounidenses y en éstas la cidh ha determinado que tiene jurisdicción para conocer de estos casos y para determinar si hubo o no violaciones por parte de los agentes estatales de dicho Estado bajo la DADDH.

\section{CASOS ILUSTRATIVOS SOBRE ASPECTOS DEL SISTEMA INTERAMERICANO QUE CONTRIBUYEN A DELIMITAR LA LUCHA CONTRA EL TERRORISMO}

Una lectura ilustrativa de las diversas dimensiones de acción del sistema interamericano frente a medidas antiterroristas, la ofrecen, de una parte, la forma como la CIDH fue reaccionando después del 11 de septiembre de 2001 frente a las acciones de los EUA en Guantánamo y otros lugares, y de otra, estándares sobre limitaciones y restricciones de derechos que la cidh ha ido desarrollado con relación a medidas y prácticas usualmente utilizadas por los Estados, para controlar y prevenir el terrorismo, como es el caso de las inspecciones corporales para la detección de explosivos.

\section{LOS INFORMES DE LA COMISIÓN INTERAMERICANA DE DERECHOS HUMANOS Y LA SITUACIÓN EN GUANTÁNAMO}

En el contexto de peticiones individuales, la CIDH tiene la potestad de decretar medidas cautelares ${ }^{54}$ contra cualquier Estado miembro de la oea con relación a situaciones de carácter grave y urgente ${ }^{55}$. Estas medidas, constituyen una de las herramientas más importantes y ágiles que tiene la CIDH para confrontar cierto tipo de medidas estatales adoptadas como reacción de ciertos Estados a acciones terroristas. Un ejemplo de ello es la reacción de la CIDH desde el año 2002, cuando comenzó a emitir una serie de medidas cautelares contra EUA, solicitándole que suministrara información acerca de los detenidos en la base naval de la bahía de Guantánamo, que clarificara el estatus legal de los detenidos, que les otorgara las garantías correspondientes y que les respetara el 
mínimo de garantías y de derechos no derogables, reconocidos en el sistema interamericano ${ }^{56}$.

El 12 de marzo de 2002, la cidh otorgó las primeras medidas cautelares a favor de los etenidos de la bahía de Guantánamo ${ }^{57}$. En un principio la cidh enfocó las medidas cautelares en la necesidad de que un tribunal competente determinara el estatus jurídico de las personas detenidas y en que se les otorgara los mecanismos legales de protección acordes con su situación jurídica. Sin embargo, en esta decisión la cidh también determinó que EUA estaba encargado de asegurarles los derechos a los detenidos porque, aunque la base naval de Guantánamo no se encontraba en territorio norteamericano, claramente estas personas se hallaban bajo la autoridad y el control de las autoridades estadounidenses ${ }^{58}$.

El 12 de abril de 2002, EUA presentó sus observaciones a las medidas cautelares decretadas por la CIDH, en donde argumentó que la cidh carecía de jurisdicción para aplicar normas de DIH y para decretar medidas cautelares contra miembros de la oea que no hubiesen ratificado la $\operatorname{cadh}^{59}$. El 23 de julio la CIDH respondió que rechazaba las objeciones de jurisdicción que había realizado EUA y mantenía las medidas cautelares decretadas el 12 de marzo ${ }^{60}$. Asimismo, reiteró su solicitud de información y mostró su preocupación por la nueva información de que existían personas detenidas en Guantánamo que habían sido capturadas en Bosnia y Pakistán, lo cual, a criterio de la CIDH, generaba dudas razonables acerca del estatus jurídico de los detenidos y sobre los derechos y garantías a las cuales tenían derecho estas personas, en la medida que no era claro si los detenidos pertenecían o no a fuerzas armadas enemigas ${ }^{61}$.

La CIDH, en marzo de 2003, emitió otro comunicado en donde expresa su gran preocupación por las reiteradas denuncias acerca del posible maltrato al que estaban siendo sometidos los detenidos. En este sentido, la CIDH recordó las recomendaciones hechas en el Informe sobre Terrorismo y Derechos Humanos de 2002 concernientes al derecho a recibir un trato humano ${ }^{62}$. De igual forma, y teniendo en cuenta la ausencia de información por parte de EUA, la cidh decidió reiterar las medidas cautelares, ya decretadas, y solicitó que se le suministrara información específica sobre las denuncias de maltrato y tortura. En particular, solicitó que se le informara sobre la ubicación, el estatus y tratamiento otorgado a las personas detenidas por EUA, no solamente en la base naval de la bahía de Guantánamo, sino en cualquier otro centro de detención, sobre el cual ejerciera control, y que además se le informara sobre las políticas y prácticas de tratamiento a los detenidos, específicamente aquellas que prohibieran tratos que alcancen el nivel de tortura o de trato cruel, inhumano o degradante ${ }^{63}$.

En julio de 2004, la CIDH nuevamente reiteró y adicionó las medidas cautelares a favor de los detenidos en la bahía de Guantánamo. Esta vez la cidh reaccionó, ante las denuncias de maltrato por parte de personas que habían estado detenidas en la base naval, a los reportes del Comité Internacional de la Cruz Roja, pero principalmente, a un memorando gubernamental de carácter interno ${ }^{64}$ que se filtró a los medios de comunicación y en el cual se hacían manifiestas las políticas de maltrato a las que estaban siendo sometidos los detenidos. En esta comunicación, la CIDH decidió solicitar información adicional sobre las medidas, que hasta el momento EUA había adoptado. De igual forma, le solicitó a EUA que adoptara todas las medidas necesarias para conducir investigaciones independientes, imparciales y efectivas con relación a los hechos alegados de tortura, teniendo en cuenta que dichas investigaciones no debían limitarse a los perpetradores directos, sino a los mandos superiores ${ }^{65}$. Asimismo, hizo mención a las denuncias que indicaban que existían menores de 18 años detenidos en la bahía de Guantánamo y que dichas detenciones no estaban siendo llevadas de acuerdo a los estándares internacionales vigentes en la materia ${ }^{66}$, por lo que la cidh decidió requerir a EUA que suministrara esa información al respecto. Finalmente, la cidh al referirse al estatus jurídico de los detenidos observó que la decisión de la Corte Suprema de EUA, 
en el caso Rasul vs. Bush ${ }^{67}$ concerniente a que las Cortes Federales tienen competencia para determinar la legalidad de la detención ${ }^{68}$, podía considerarse como una base importante para que el gobierno cumpliera con las medidas cautelares decretadas por la CIDH y que a su vez facilitaría el procedimiento para establecer el estatus jurídico de los detenidos y para asegurarles las garantías judiciales a las que tienen derecho.

En diciembre de 2004, los EUA respondieron a la CIDH, alegando nuevamente que la ésta carecía de jurisdicción para decretar medidas cautelares en contra los EUA. Sin embargo, esta vez, EUA argumentó que, hasta la fecha, los recursos internos no habían sido agotados y que, por ende, la cidh no tenía competencia para conocer el caso ${ }^{69}$. El 28 de octubre de 2005, la CIDH dio respuesta a la comunicación del Estado, mencionando que los asuntos jurisdiccionales y de competencia ya estaban claramente definidos en el sistema interamericano y aclaró que en el caso de las medidas cautelares no era necesario agotar los recursos internos, precisamente por el carácter de urgencia y gravedad que las revestía ${ }^{70}$. Adicionalmente, la CIDH le solicitó al gobierno de EUA que garantizara que los detenidos en la bahía de Guantánamo no iban a ser trasladados a países donde existieran motivos fundados para creer que éstos estarían en peligro de ser sometidos a tortura u otros maltratos ${ }^{71}$. La CIDH tam bién le solicitó a EUA que no permitiera que las declaraciones obtenidas bajo tortura se utilizaran como prueba en los distintos procedimientos legales ${ }^{72}$. De igual forma, la CIDH reconoció la importancia de las investigaciones que se estaban adelantando con relación a las denuncias de torturas; sin embargo, resaltó que el sistema que se estaba utilizando no era lo suficientemente independiente y que, por lo tanto, el Departamento de Defensa no debía continuar a cargo de las investigaciones ${ }^{73}$. Finalmente, la CIDH reiteró su solicitud concerniente a que un tribunal competente estableciera el estatus jurídico de los detenidos en la bahía de Guantánamo, resaltando el hecho de que los tribunales y procedimientos militares establecidos para tal efecto no estaban arrojando los resultados esperados, y que, por lo tanto, los detenidos aún continuaban sin tener acceso a un recurso adecuado y efectivo de hábeas corpus.

Finalmente, en julio de 2006, la CIDH reiteró lo establecido en las anteriores medidas cautelares y adicionalmente exhortó al gobierno de EUA al cierre inmediato del centro de detención, así como a trasladar a los detenidos.

El proceso descrito es un ejemplo importante del tipo de acción que puede desplegar la CIDH frente a situaciones en las que las medidas antiterroristas de un Estado parecen vulnerar normas internacionales de derechos humanos. La CIDH tiene la capacidad de responder en forma rápida, utilizando su sistema de medidas cautelares, aunque su efectividad está limitada por la voluntad que el Estado tenga de cumplir con esas órdenes. De igual forma, la CIDH puede recurrir simultáneamente a tramitar casos individuales, con relación a las mismas situaciones que fueron objeto de las medidas cautelares, resultando en la determinación de responsabilidad internacional, si fuese el caso.

\section{RESTRICCIONES Y LIMITACIONES DE LOS DERECHOS HUMANOS}

Un tema importante, con relación a los alcances y límites de las medidas antiterroristas, es el relacionado con las restricciones y limitaciones autorizadas de derechos humanos ${ }^{74}$. Los parámetros que se fijan a través de los estándares elaborados en la jurisprudencia y casuística del sistema tienen singular importancia debido a que presentan en forma muy puntual y clara cómo los operadores nacionales deben diseñar medidas de control que no contravengan las normas internacionales. Con base en esas decisiones y sentencias se puede, entonces, establecer cuáles deben ser los criterios que debe atender dicho operador al adoptar ciertas medidas y cómo debe razonar para ajustarse a la cadh, entre otros instrumentos. 
Un caso ilustrativo en este aspecto es el caso X y Y vs. Argentina, 75 en el cual la CIDH examinó las medidas adoptadas por las autoridades argentinas para inspeccionar personas a la entrada de una prisión, entre éstas se encontraban inspecciones vaginales. Aunqueel caso no tiene que ver directamente con la lucha contra el terrorismo, está relacionado con las actividades de control personal, que usualmente se implementan para prevenir el transporte de armas y explosivos, e indica la manera de cómo las autoridades deben obrar al diseñar medidas de control que persiguen un fin legítimo, pero que pueden llegar a interferir con un derecho fundamental de las personas protegido en la $\mathrm{CADH}$.

El 29 de diciembre de 1989, la CIDH recibió una denuncia en contra del gobierno de Argentina, con relación a la situación de la señora $X$ y su hija $Y$ de 13 años. Estas dos mujeres visitaban a su esposo y padre en la Cárcel de Encausados de la Capital Federal, y en las visitas fueron sometidas a revisiones vaginales ${ }^{76}$. Las autoridades penitenciarias establecieron la práctica de realizar estas inspecciones a todas las mujeres que tuvieran contacto personal con los reclusos, debido a que se estaban ingresando drogas y narcóticos a la prisión. El 31 de marzo de 1989, durante una inspección de rutina, se encontró en la celda del marido de la señora $X$ un frasco con un líquido amarillo y 400 gramos de explosivos plásticos ${ }^{77}$. Cuando la señora $X$ y su hija $Y$ se presentaron a visitar al recluso el día 2 de abril las autoridades penitenciarias les informaron que para poder tener contacto con el recluso se debían someter a una inspección vaginal o de lo contrario la visita se llevaría a cabo a través de un vidrio.

El 23 de enero de 1990, la CIDH recibió el caso y entró a analizar dos aspectos específicos. El primero de ellos consistente en determinar si el requisito de someterse a una inspección vaginal, previa a una visita de contacto personal, es congruente con los derechos y garantías establecidos en la $\mathrm{CADH}$, y el segundo en establecer si la revisión a la que fueron sometidas, privó a las dos mujeres del pleno goce de algunos derechos protegidos en la CADH tales como el derecho al trato humano, la protección de la honra y de la dignidad, la protección a la familia y los derechos del niño, junto con la obligación de los Estados parte de respetar y garantizar el pleno y libre ejercicio de todas las disposiciones reconocidas en la CADH sin discriminación alguna ${ }^{78}$. Después de un detallado análisis, la CADH concluyó que para establecer si las medidas se adecuaban a lo dispuesto en la CADH tales medidas debían cumplir con tres condiciones específicas, a saber:

1. Debe ser prescrita por la ley.

2. Debe ser necesaria para la seguridad de todos y guardar relación con las demandas justas de una sociedad democrática.

3. Su aplicación se debe ceñir estrictamente a las circunstancias específicas enunciadas en el artículo 32.2 [de la $\mathrm{CADH}$ ], y ser proporcional y razonable a fin de lograr esos objetivos ${ }^{79}$.

Teniendo en cuenta lo anterior, la CIDH concluyó, en primer lugar, que la revisión o inspección vaginal debe ser regulada “...por una ley que especifique claramente en qué circunstancias se puede imponer una medida de esa naturaleza y que enumere las condiciones que deben ser observadas por

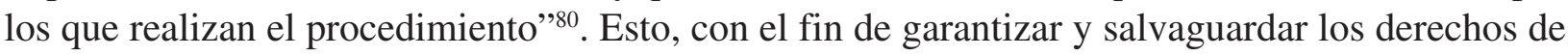
las personas sujetas a tales medidas. En segundo lugar, la CIDH estableció que las revisiones o inspecciones vaginales son procedimientos excepcionales e intrusivos. Por lo tanto, el visitante o miembro de la familia que procure ejercer su derecho a una vida familiar, no debe convertirse automáticamente en sospechoso y, en principio, no puede considerarse como una amenaza grave para la seguridad. Es por eso que, aunque las inspecciones vaginales se pueden llevar a cabo excepcionalmente con el fin de garantizar la seguridad en ciertos casos específicos, no se puede argumentar que su aplicación sistemática a todos los visitantes sea una medida necesaria para garantizar la seguridad pública ${ }^{81}$. 
La CIDH igualmente concluyó que la razonabilidad y proporcionalidad de una medida se pueden determinar únicamente con base en cada caso específico ${ }^{82}$. Además sostuvo que para establecer la legitimidad excepcional de una revisión o inspección vaginal, se deben cumplir cuatro requisitos, a saber:

1. Tiene que ser absolutamente necesaria para lograr el objetivo de seguridad en el caso específico;

2. No debe existir alternativa diferente;

3. Debería, en principio, ser autorizada por orden judicial;

4. Debe ser realizada únicamente por profesionales de la salud ${ }^{83}$.

La CIDH estableció que este tipo de medidas no deben aplicarse, a no ser que sean absolutamente necesarias para lograr el objetivo de seguridad en un caso en particular, y definió el requisito de necesidad en el sentido en que dichas medidas se deben realizar únicamente en casos específicos cuando existen motivos para creer que hay un peligro real para la seguridad.

Así, la CIDH estableció que había otros mecanismos menos restrictivos, tales como requisar a los internos después de las visitas o mantener un estricto control sobre las celdas ${ }^{84}$. La CIDH también concluyó que la realización de este tipo de requisas corporales, sólo deberían estar a cargo de profesionales de la salud, con la estricta observancia de seguridad e higiene, dado el posible riesgo de daño físico y moral al cual se puede someter a una persona ${ }^{85}$. Adicionalmente, estableció que las inspecciones vaginales pueden ser aceptables bajo ciertas circunstancias, siempre y cuando ésta se ajuste a los derechos protegidos por la $\mathrm{CADH}$. Es decir, que si no se cumplen con los estándares de legalidad, necesidad y proporcionalidad y si el procedimiento no se lleva a cabo con el debido respeto de ciertos requisitos que protegen la legitimidad de la acción y la integridad física de las personas, se puede concluir que los derechos consagrados en la CADH han sido violados ${ }^{86}$.

Finalmente, la CIDH consideró que la inspección vaginal es una intrusión tan íntima al cuerpo de una persona, que exige una protección especial, ya que cuando la decisión de someter a una persona a esta clase de inspecciones, queda a discreción total de la policía o del personal de seguridad, existe la posibilidad de que se practique innecesariamente y se convierta en una práctica abusiva. Por ello, la determinación de que este tipo de inspección se convierta en un requisito necesario para poder gozar del derecho a las visitas, deberá ser efectuada únicamente por autoridades judiciales ${ }^{87}$.

Evidentemente, es posible analizar una analogía entre este caso y otras actividades, tales como el control fronterizo, control de aeropuertos o de otros lugares sensibles, donde el Estado se confronta con la necesidad de adoptar medidas limitativas de ciertos derechos de las personas para preservar la seguridad pública. La CADH y la Convención Interamericana contra el Terrorismo confluyen para apoyar y requerir del Estado su acción contra posibles hechos terroristas que puedan afectar a las personas bajo su jurisdicción. Pero de la misma manera, la CADH establece los límites de la actuación del Estado frente a la posible interferencia de los derechos de otras personas, ya sean presuntos terroristas, familiares, miembros de ciertos grupos, etcétera. 


\section{CONCLUSIÓN}

El sistema interamericano está dotado de múltiples mecanismos que le permiten, tanto a la cidh como a la CorteIDH fijar parámetros básicos que los Estados deben seguir al momento de adoptar medidas antiterroristas. Como queda evidenciado, la CADH y demás instrumentos de derechos humanos del sistema no son insensibles a las necesidades legítimas de los Estados cuando de combatir el terrorismo se trata. Por el contrario, la CADH exige a los Estados prevenir y castigar aquellas acciones que puedan afectar derechos fundamentales de las personas (vida, integridad personal, etc.), que es una obligación análoga a aquélla contenida en la Convención Interamericana

contra el Terrorismo. Por lo tanto, al tomar medidas antiterroristas, los Estados, en esencia, están descargando sus obligaciones bajo ambos tratados internacionales. Mas esas potestades noson ilimitadas, ya que la CADH también establece límites a la forma como puede combatirse el terrorismo cuando podrían afectarse los derechos de otras personas, lo cual también ha sido reconocido expresamente por la Convención Interamericana contra el Terrorismo. Por lo tanto, sí es posible interpretar estos regímenes en forma armónica, ya que tienden a reforzarse mutuamente.

\section{NOTAS}

* Este artículo es una trascripción modificada y referenciada de la presentación realizada en el Seminario Internacional Derechos Humanos y Terrorismo que se llevó a cabo en México el 12 de septiembre del 2006. Las páginas de internet citadas se consultaron en abril del 2007.

${ }^{1}$ Comisión Interamericana de Derechos Humanos (cidh), Informe sobre Terrorismo y Derechos Humanos. 22 de octubre de 2002. (oea/Ser.L/V/ll.116 Doc. 5 rev. 1).

${ }^{2}$ La cidh menciona en su Informe sobre Terrorismo y Derechos Humanos como hechos notorios de acciones terroristas: i) la detonación de una bomba en un vuelo de pasajeros de Cubana de Aviación que había salido de Caracas; ii) la detonación de una bomba el 18 de julio de 1994 en la Asociación Mutual Israelita Argentina en Buenos Aires; iii) la toma de rehenes en la Embajada de Japón en Lima, Perú, en diciembre de 1996, y iv) el secuestro en Colombia del vuelo 9463 de Avianca en su ruta Bucaramanga-Bogotá.

${ }^{3} \mathrm{CIDH}$, Informe sobre Terrorismo y Derechos..., op. cit.

${ }^{4}$ Ibid., párr. 2.

${ }^{5}$ Idem.

${ }^{6}$ cidh, Informe Anual de la Comisión Interamericana de Derechos Humanos 1990-1991.

22 de febrero de 1991, capítulo V, p. 512 (oea/Ser.L/VII.79 rev. 1 Doc.).

${ }^{7}$ Entre las más relevantes están la Convención Americana sobre Derechos Humanos. Adoptada en San José de Costa Rica el 22 de noviembre de 1969, en la Conferencia Especializada Interamericna sobre Derechos Humanos. Entró en vigor el 18 de julio de 1978. La Convención Interamericana para Prevenir y Sancionar la Tortura. Adoptada en Cartagena de Indias, Colombia, el 9 de diciembre de 1985, en el decimoquinto periodo ordinario de sesiones de la Asamblea General de la Organización de Estados Americanos. Entró en vigor el 28 de febrero de 1987. Convención Interamericana sobre Desaparición Forzada de Personas.

Adoptada en Belen do Pará, Brasil, el 9 de junio de 1994, en el vigésimo cuarto periodo ordinario de sesiones de la Asamblea General de la Organización de Estados Americanos. Entró en vigor el 28 de marzo de 1996.

${ }^{8}$ Convención Interamericana contra el Terrorismo. Adoptada por la Asamblea General de la Organización de Estados Americanos en su Segunda sesión plenaria, 3 de junio de 2002 [OAS AG/RES.1840 (XXXII-O/ 02)]. 
${ }^{9}$ Convención Americana sobre Derechos.., op. cit., art. 1.

${ }^{10}$ Convención Interamericana contra el Terrorismo..., op. cit., art. 1.

${ }^{11}$ Ibid., art. 15.

${ }^{12}$ Idem.

${ }^{13}$ Corteidh, La Expresión "Leyes" en el Artículo 30 de la Convención Americana sobre Derechos Humanos, Opinión Consultiva O-C 6/86 del 9 de mayo de 1986, Serie A núm. 6, párr. 14. Véase Claudio Grossman, "El régimen hemisférico sobre situaciones de emergencia", en Estudios Básicos de Derechos Humanos I. 1994. Véase cidh, Informe sobre Terrorismo y Derechos..., op. cit., párr. 52 y 53.

${ }^{14}$ Convención Americana sobre Derechos..., op. cit., art. 27.

${ }^{15}$ Idem.

16 El articulo 27 de la cadh no autoriza la suspensión del derecho al reconocimiento de la personalidad jurídica, el derecho a la vida, el derecho a la integridad personal, la prohibición de la esclavitud y servidumbre, el principio de legalidad y de retroactividad, la libertad de conciencia y de religión, la protección a la familia, el derecho al nombre, los derechos del niño, el derecho a la nacionalidad, los derechos políticos ni de las garantías judiciales indispensables para la protección de tales derechos.

${ }^{17} \mathrm{CIDH}$, Informe sobre Terrorismo y Derechos..., op. cit. párr. 49-56.

${ }^{18}$ CorteIDH, Garantías Judiciales en Estados de Emergencia. Art. 27.2, 25 y 8. cadh Americana sobre Derechos Humanos. Opinión Consultiva OC-9/87 del 6 de octubre de 1987. Serie A núm. 9, párr. 25.

${ }^{19}$ Convención Americana sobre Derechos..., op. cit., art. 41. c; oea, Estatuto de la Comisión Interamericana de Derechos Humanos. Adoptado mediante la Resolución núm. 447 de la Asamblea General de la Organización de Estados Americanos en su noveno periodo ordinario de sesiones, celebrado en La Paz, Bolivia en octubre de 1979. [Reglamento de la Comisión Interamericana de Derechos Humanos]. Adoptado por la Comisión en su $109^{\circ}$ periodo de sesiones, celebrado del 4 al 8 de diciembre de 2000, y modificado en su $116^{\circ}$ periodo de sesiones celebrado del 7 al 25 de octubre de 2002 , en su 118 periodo de sesiones, celebrado del 6 al 24 de octubre de 2003, y en su $126^{\circ}$ periodo de sesiones celebrado del 16 al 27 de octubre de 2006.

${ }^{20}$ Consejo Permanente de la oea, Recomendaciones para la Protección de los Derechos Humanos por parte de los Estados Miembros de la oea en la Lucha contra el Terrorismo. 9 de mayo de 2006. (oea/Ser. G CP/ doc.411 7/06) Antecedentes y Contexto punto 4. (En adelante, Recomendaciones para la Lucha contra el Terrorismo).

${ }^{21} \mathrm{CIDH}$, Informe sobre Terrorismo y Derechos..., op. cit., párrs. 57, 61 y 62.

22 bid., punto 9.

${ }^{23}$ oea, La Protección de los Derechos Humanos y las Libertades Fundamentales en la Lucha contra el Terrorismo del 8 de junio de 2004. Punto resolutivo 6. (AG/RES. 2035 (XXXIV-O/04))

${ }^{24}$ Idem.

${ }^{25}$ Consejo Permanente de la oea, Recomendaciones para la Lucha contra el Terrorismo..., op. cit., Antecedentes y Contexto, punto 5 .

${ }^{26}$ Ibid., punto 6. 
${ }^{27}$ oea, La Protección de los Derechos Humanos..., op. cit. punto resolutivo 6.

${ }^{28}$ oea, Estatuto de la Comisión Interamericana..., op. cit., art. 18.c. Convención Am ericana sobre..., op. cit., art. 41.c.

${ }^{29} \mathrm{CIDH}$, Tercer Informe sobre la Situación de los Derechos Humanos en Colombia. 26 de febrero de 1999. (oea/Ser.L/V/II.102 Doc. 9 rev. 1).

${ }^{30}$ Protocolo adicional a los Convenios de Ginebra del 12 de agosto de 1949 relativo a la protección de las víctimas de los conflictos armados sin carácter internacional (Protocolo II). Adoptado el 8 de junio de 1977, por la Conferencia Diplomática sobre la Reafirmación y el Desarrollo del Derecho Internacional Humanitario, aplicable a los Conflictos Armados. Entró en vigor el 7 de diciembre de 1978. Disponible en $<$ http://www.unhchr.ch/spanish/html/intlinst_sp.htm>.

${ }^{31}$ Artículo II común de los cuatro Convenios de Ginebra. Adoptado el 12 de agosto de 1999 por la Conferencia Diplomática para Elaborar Convenios Internacionales destinados a proteger a las víctimas de la guerra, celebrado en Ginebra del 12 de abril al 12 de agosto de 1949. Entró en vigor el 21 de octubre de 1950. Disponible en <http://www.unhchr.ch/spanish/html/intlinst_sp.htm>.

${ }^{32}$ CORTEIDH, Caso Castillo Petruzzi y Otros vs. Perú. Fondo Reparaciones y Costas. Sentencia de 30 de mayo de 1999. Serie C No. 52.

${ }^{33}$ CORTEIDH, Caso Loayza Tamayo vs. Perú. Fondo Reparaciones y Costas. Sentencia de 17 de septiembre de 1997. Serie C No. 33.

${ }^{34}$ Véase Corteidh, Caso Cesti Hurtado vs. Perú. Sentencia de 29 de septiembre de 1999. Serie C núm. 56; Corteidh. Caso Ivcher Bronstein vs. Perú. Fondo, Reparaciones y Costas. Sentencia de 6 de febrero de 2001. Serie C núm. 74; Corteidh. Caso Barrios Altos vs. Perú. Fondo Reparaciones y Costas. Sentencia de 14 de marzo de 2001. Serie C núm. 75; Corteidh. Caso Lori Berenson Mejía vs. Perú. Fondo, Reparaciones y Costas. Sentencia de 25 de noviembre de 2004. Serie C núm. 11 9; Corteidh. Caso del Penal Miguel Castro Castro vs. Perú. Fondo, Reparaciones y Costas. Sentencia de 25 de noviembre de 2006. Serie C núm. 160; Corteidh. Caso La Cantuta vs. Perú. Fondo, Reparaciones y Costas. Sentencia de 29 de noviembre de 2006 Serie C núm. 162.

${ }^{35}$ cidh, Informe sobre Terrorismo y Derechos Humanos. 2 de octubre 2002, (oea/Ser.L/V/ll.116 Doc. 5 rev. 1)2. párr. 164.

${ }^{36}$ Corteidh, Caso Loayza Tamayo vs. Perú..., op. cit., párr. 57.

${ }^{37}$ Idem.

${ }^{38}$ Idem.

${ }^{39}$ Corteidh, Caso Velásquez Rodríguez vs. Honduras. Fondo, Reparaciones y Costas. Sentencia de 29 de julio de 1988. Serie C núm. 4.

${ }^{40}$ Corteidh, Caso Bámaca Velásquez vs. Guatemala. Fondo, Reparaciones y Costas. Sentencia de 25 de noviembre de 2000. Serie C núm. 70.

${ }^{41}$ Corteidh, Caso Velásquez Rodríguez vs. Honduras..., op. cit., párr.54.

${ }^{42}$ Corteidh, Caso Barrios Altos vs. Perú..., op. cit. 
${ }^{43}$ Ibid., párr. 41. Sobre otros casos de la Corteidh sobre amnistías véase casos Almonacid Arellano y otros vs. Chile, Excepciones Preliminares, Fondo, Reparaciones y Costas. Sentencia del 26 de septiembre de 2006, Serie C núm. 154, y La Cantuta vs. Perú. fondo, Reparciones y Costas. Sentencia de 29 de noviembre del 2006, Serie C núm. 162.

${ }^{44}$ Corteidh, Caso Barrios Altos vs. Perú. Interpretación de la Sentencia de Fondo (art. 67 Convención Americana sobre Derechos Humanos). Sentencia de 3 de septiembre de 2001. Serie C núm. 83, párr. 18.

${ }^{45}$ cidh, Informe 28/92, Argentina, Informe Anual de la Comisión Interamericana de Derechos Humanos 1992-1993, párr. 41; cidh. Informe 29/92, Uruguay, Informe Anual de la Comisión Interamericana de Derechos Humanos 1992-1993, párr. 51; cidh. Informes 34/96 y 36/96, Chile, Informe Anual de la Comisión Interamericana de Derechos Humanos 1996, párrs. 76 y 78 respectivamente; cidh. Informe 25/98, Chile, Informe Anual de la Comisión Interamericana de Derechos Humanos 1997, párr. 71 y cidh. Informe 1/99, El Salvador, Informe Anual de la Comisión Interamericana de Derechos Humanos 1998, párr. 170.

${ }^{46}$ Corteidh, Caso Masacre de Pueblo Bello vs. Colombia. Fondo, Reparaciones y Costas. Sentencia de 31 de enero de 2006. Serie C núm. 140.

${ }^{47}$ Aunque de cierta forma le estaba dando continuidad a la teoría de las obligaciones Erga Omnes, en donde la CorteIDH ya había mencionado que el Estado está llamado a garantizar el respeto de los derechos "...tanto en las relaciones entre los individuos y el poder público estatal, como en las relaciones inter-individuales". CorteIDH. Condición Jurídica y Derechos de los Migrantes Indocumentados. Opinión Consultiva OC-18/ 03 del 17 de septiembre de 2003. Serie A núm. 18.

${ }^{48}$ CorteIDH, Caso Masacre de Pueblo Bello vs. Colombia..., párr. 123.49 Ibid., párr. 124, citando, European Court of Human Rights, Osman vs. the United Kingdom judgment of 28 October 1998, Reports of Judgments and Decisions 1998-VIII, párrs. 115 -116.

${ }^{50}$ oea, Estatuto de la Comisión Interamericana..., op. cit., art. 20.

${ }^{51}$ oea, Reglamento de la Comisión Interamericana..., op. cit., arts. 28-43.

${ }^{52}$ EUA ha refutado esta atribución de la cidh. Véase Respuesta del Gobierno de los Estados Unidos de Norte América a la Comisión Interamericana de Derechos Humanos, Informe 85/00 de 23 de octubre de 2000 relativo a Mariel Cubans (en inglés), disponible en <http://www.cidh.org/Respuestas/USA.9903.htm>.

${ }^{53} \mathrm{La}$ DADDH se considera como fuente de obligaciones para todos los Estados miembros de la oea. Véase Corteidh. Interpretación de la Declaración Americana de los Derechos y Deberes del Hombre en el Marco del Artículo 64 de la cadh Americana sobre Derechos Humanos. Opinión Consultiva OC-10/89 del 14 de julio de 1989. Serie A núm. 10, párrs. 35-45.

${ }^{54} \mathrm{La}$ CIDH reafirmó la obligación que tienen los Estados miembros de la oea de acatar las solicitudes de medidas cautelares. Véase cidh, Informe Anual de la Comisión Interamericana de Derechos Humanos 1997. 13 de abril de 1998. (oea/Ser.L/V/II.98 Doc. 6 rev.), capítulo VII, párr. 12; véase también, cidh, Resolución 1/05 del 8 de marzo de 2005, párr. 9 y punto resolutivo 1. Disponible en <http://www.cidh.org/ resolucion1.05.htm>.

${ }^{55}$ Reglamento de la Comisión Interamericana..., op. cit., art. 25.

${ }^{56}$ Guantanamo Bay Precautionary Measures. March 12, 2002. Disponible en <http://www.ccr-ny.org/v2/ legal/september_11 th/docs/3-13-02\%20IACHRAdoptionofPrecautionaryMeasures.pdf $>$ Sobre estas medidas también véase Brian D. Tittemore, "Guantanamo Bay and the Precautionary Measures of the InterAmerican Commission on Human Rights: A Case for International Oversight in the Struggle Against Terrorism", en Human Rights Law Review, Oxford University Press, 2006. Disponible en <http:// hrlr.oxfordjournals.org/cgi/reprint/6/2/378>. 
${ }^{57}$ Ibid., p. 3.

${ }^{58}$ Idem.

${ }^{59}$ State's Response delivered on April 12, 2002. Disponible en <http://www.ccr-ny.org/v2/legal/september.11 th/docs/4-15-02GovernmentResponse.pdf>.

${ }^{60}$ Guantanamo Bay Precautionary Measures Communication. July 23, 2002 from iachr President Juan E. Mendez to US Secretary of State Colin Powell, p. 2.Disponible en <http://www.ccr-ny.org/v2/legal/ september_11 th/docs/7-23-02GovtResponsetoObservations_andIACHR_Decision.pdf $>$.

${ }^{61}$ Ibid., p. 3.

${ }^{62}$ Guantanamo Bay Precautionary Measures Communication of March 18, 2003 from the iachr to us Secretary of State Colin Powell. El texto del comunicado del 18 de marzo de 2003 a los representantes de los detenidos, contiene las partes pertinentes del comunicado hecho al Estado y se encuentra disponible en $<$ http://www.ccrny.org/v2/reports/docs/iachr-TortureLetter.pdf>.

${ }^{63}$ Ibid., p. 3.

${ }^{64}$ June 28, 2004 observations from the detainees' representatives to the iachr, pp. 2-8.

${ }^{65}$ Guantanamo Bay Precautionary. Measures Communication. July 29, 2004 from the Executive Secretary of the Commission to US Secretary of State Colin Powell. Disponible en <http://www.ccr-ny.org/v2/legal/ september_11 th/docs/IACHRCommisionsPMsJuly2004.pdf>; (2006) 45 International Legal Materials 671, p. 3 .

${ }^{66}$ Convención sobre los Derechos del Niño. Resolución de la A.G. 44/25. 20 de noviembre de 1989. Anexo 44, onu gaor Supp. (núm. 49), 167, onu Doc. A/44/49 (1989). Art.37

${ }^{67}$ Caso Rasul vs. Bush. [542 US 466 (2004)]

${ }^{68}$ Idem.

${ }^{69}$ State's observations of October 19, 2005, pp. 1-5.

${ }^{70}$ Guantanamo Bay Precautionary Measures Communication. October 28, 2005 from the President of the iachr to US Secretary of State Condoleezza Rice. El texto del comunicado del 28 de octubre de 2003 a los representantes de los detenidos, contiene las partes pertinentes del comunicado hecho al Estado y se encuentra disponible en <http://www.ccr-ny.org/v2/legal/september_11 th/docs/ IACHR_10280PrecautionaryMeasures.pdf>.

${ }^{71}$ Idem.

72 Idem.

73 Idem.

74 Convención Americana sobre..., op. cit., art. 30.

75 CIDH, X y Y vs. Argentina. Caso 10.506, Informe núm. 38/96, 15 de octubre de 1996. Disponible en $<$ http://www.cidh.org/annualrep/96span/Argentina10506.htm>.

76 Ibid., párr. 1. 
${ }^{77}$ Ibid., párr. 5.

${ }^{78}$ Ibid., párr. 47.

${ }^{79}$ Ibid., párr. 60.

${ }^{80} \mathrm{Ibid}$., párr. 64.

${ }^{81}$ Ibid., párr. 68.

${ }^{82}$ Ibid., párr. 71.

${ }^{83}$ Ibid., párr. 72.

${ }^{84}$ Ibid., párr. 76.

${ }^{85}$ Ibid., párr. 84.

${ }^{86}$ Ibid., párr. 78.

${ }^{87}$ Ibid., párr. 82. 